\title{
Adherens Junctions: Demonstration in Human Epidermis
}

\author{
Hans W. Kaiser, Winfried Ness, Isabel Jungblut, Robert A. Briggaman, Hans W. Kreysel, and Edward J. O'Keefe \\ Department of Dermatology (HWK, WN, IJ, HWK), University of Bonn, Bonn, Germany; and Department of Dermatology (RAB, \\ EJO'K), University of North Carolina, Chapel Hill, North Carolina, U.S.A.
}

Adherens junctions are intercellular and cell-matrix junctions that, like desmosomes and hemidesmosomes, mediate adhesion of cells to each other or to matrix structures. These junctions have been detected recently in cultured human keratinocytes, indicating that they may be of importance in epidermis. To investigate the localization of adherens junctions in normal epidermis, we examined human epidermis, human oral mucosa, and monkey esophagus for the presence of vinculin, a major protein of the intracellular plaques of adherens junctions that is thought to be present in all adherens junctions. Western blot analysis demonstrated vinculin in extracts of epidermis. Immunohistochemistry of vinculin in these tissues displayed two distinct locations for adherens junctions: i) at the dermal-epidermal junction, and ii) in the region of cell-cell contacts in all layers of the epidermis. The location of vinculin in the region of the epidermal-dermal junction is reminiscent of the distribution of vinculin-containing focal contacts in cultured keratinocytes, and the intercellular staining of vinculin in epidermis is consistent with the presence of vinculin in adherens junctions in cultured keratinocytes at sites of cell-cell contact. These results demonstrate that adherens junctions are present in human epidermis, oral mucosa, and monkey esophagus. Vinculin-containing junctions in epidermis may be important in the pathogenesis of skin diseases involving alterations in intercellular integrity. J Invest Dermatol 100:180-185, 1993

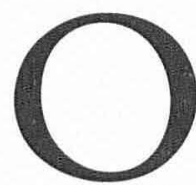

$f$ the four types of intercellular junctions, gap junctions, tight junctions, desmosomes, and adherens junctions, two, namely the desmosome and the adherens junction, are thought to serve the purpose of cell-cell adhesion and are referred to as adhering junctions. Desmosomes, which are associated with keratin filaments, are thought to be the major adhering junctions responsible for the attachment of cells $[1,2]$. In addition to desmosomes, adherens junctions, which are associated with actin filaments, can be identified in tissues such as intestinal epithelium, muscle cells, and cornea [3-7]. Adherens junctions are a heterogeneous group of cell contacts but all contain three molecular domains, i.e., microfilaments, an intracellular plaque, and a membrane domain (see [8] for review).

Three different types of adherens junctions have been demonstrated in tissues and cultured cells situated at sites of cell-matrix and cell-cell contacts. The focal contact, which is found in vitro at sites of attachment of cells to the culture surface, was identified by electron microscopy as an electron-dense region [9] in close contact with the substrate compared to other regions, leaving a reduced space between the basal aspect of the cell membrane and the culture surface. Immunocytochemical and biochemical studies revealed fibronectin and $\alpha 3 \beta 1$-integrin on the extracellular aspect [10] and alpha-actinin, talin, and vinculin on the intracellular aspect of focal adhesions (see $[11,12]$ for reviews).

At sites of cell-cell contact two morphologically distinct types of

Manuscript received April 6, 1992; accepted for publication November 2, 1992.

Reprint requests to: Dr. Hans W. Kaiser, Department of Dermatology, University of Bonn, Sigmund Freudstrasse 25, 5300 Bonn, Germany. Abbreviations:

BSA: bovine serum albumin

TBS: Tris-buffered saline adherens junctions have been described $[2,13,14]$. The first type is the classical zonula adhaerens (belt desmosome), which is located in the apical region of the lateral membrane in epithelia. It is part of the "junctional complex" in the intestinal epithelium comprising a tight junction, a zonula adhaerens (adherens junction), and desmosomes, all of which are present in an ordered structure. Zonulae adhaerentes of the junctional complex are characterized by a belt-like bundle of actin filaments [15] running circumferentially along the cytoplasmic surface of the junctional membrane. The second type, present at sites of cell-cell contact, appear by conventional electron microscopy as button-like structures similar to desmosomes. In contrast to desmosomes, adherens junctions are characterized by the presence of actin, alpha-actinin, and vinculin $[3,16]$. In all types of adherens junctions examined so far, but only in adherens junctions, vinculin, a $130-\mathrm{kDa}$ protein, has been detected in the intracellular plaque of the junction [8]. Vinculin therefore serves to identify adherens junctions in immunocytochemical investigations. We [17] and others [18] have previously demonstrated adherens junctions in cultured keratinocytes. We now report evidence for the presence of adherens junctions in epidermis. Vinculin was detected in the areas of both cell-matrix and cell-cell contact in epidermis of skin, oral mucosa, and monkey esophagus. In addition to desmosomes and hemidesmosomes, vinculin-containing adherens junctions may subserve mechanical coupling of keratinocytes to adjacent cells and also to the basement membrane.

\section{MATERIALS AND METHODS}

Keratinocyte Culture A modification of the method developed by Rheinwald and Green [19] was used to initiate cultures of normal human keratinocytes obtained from foreskins. Subcultures were grown in MCDB 153 medium with $0.1 \mathrm{mM} \mathrm{Ca}^{++}$[20] and supplements as described previously [21]. Cells were used in third or fourth passage. Intercellular contact and assembly of junctions were 

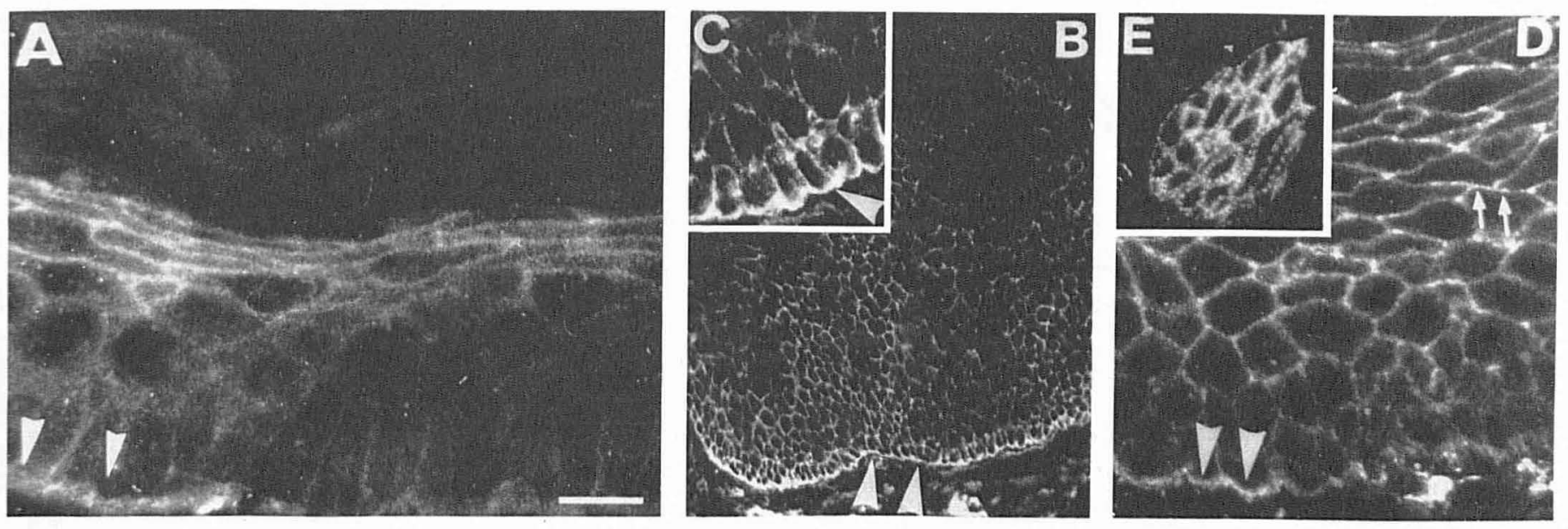

Figure 1. Demonstration of vinculin in epithelium. Tissues were stained with antibody to vinculin as in Materials and Methods. Arrowheads, region of basement membrane staining for vinculin. Arrows $(D)$, staining of regions of cell-cell contact; staining is often punctate. Muscle, a control for vinculin staining, is also shown $(E)$. A, human epidermis; $B, C$, human gingival mucosa; $D$, monkey eosphageal epithelium; $E$, monkey esophagus smooth muscle; $C$, higher magnification of $B$. Bar in $A, 20 \mu \mathrm{m}(A, D, E),, 75 \mu \mathrm{m}(B)$; or $45 \mu \mathrm{m}(C)$,

induced by changing the serum-free culture medium to fresh medium identical except for the presence of $1.1 \mathrm{mM} \mathrm{Ca}^{++}$.

Immunoblotting Studies Biopsies of normal human skin and gingival mucosa were washed in Tris-buffered saline ( $40 \mathrm{mM}$ Tris$\mathrm{HCl}, \mathrm{pH} 7.4,150 \mathrm{mM} \mathrm{NaCl}$ ) (TBS) containing $0.1 \mathrm{mM} \mathrm{Ca}{ }^{++}$. Epithelium was separated from connective tissue by heating. Tissue was placed in hot TBS $\left(95^{\circ} \mathrm{C}\right)$ with $2 \mathrm{mM}$ phenylmethylsulfonyl fluoride for $3 \mathrm{~min}$, and epithelium was collected with forceps, minced, and homogenized in Fairbanks' sample buffer [22].

Keratinocytes cultured as described above were plated at 5000 cells $/ \mathrm{cm}^{2}$ and grown for $3 \mathrm{~d}$ in $35-\mathrm{mm}$ petri dishes. After initiation of intercellular contacts, cells were washed in TBS supplemented with $0.1 \mathrm{mM} \mathrm{Ca}^{++}$and $0.1 \%$ diisopropylfluorophosphate, lysed in hot sample buffer $\left(95^{\circ} \mathrm{C}\right)$, scraped off the petri dish with a rubber policeman, and sheared with a 26-gauge needle to break DNA.

Samples were subjected to sodium dodecyl sulfate polyacrylamide gel electrophoresis using a $3.5-17 \%$ gradient gel with buffer system according to Fairbanks et al [22]. Separated proteins were transferred to nitrocellulose [23]. Non-specific binding was blocked with $4 \%$ bovine serum albumin $\left(30 \mathrm{~min}, 25^{\circ} \mathrm{C}\right)$ in TBS with $0.1 \mathrm{mM}$ $\mathrm{Ca}^{++}$. Monoclonal anti-vinculin antibodies (ICN, Meckenheim, Germany) were added in a final dilution of 1:1000 and incubated for $15 \mathrm{~h}$ at $4^{\circ} \mathrm{C}$ on a rotary shaker. Samples were washed with TBS containing $0.1 \mathrm{mM} \mathrm{Ca}{ }^{++}$and $0.1 \%$ Tween-20, peroxidase-conjugated goat anti-mouse IgG was added in a $1: 2500$ dilution for 90 $\min$ at $4^{\circ} \mathrm{C}$, and the nitrocellulose sheet was washed again. Bound antibodies were visualized using enhanced chemiluminescence (Amersham, Braunschweig, Germany) for detection of labeled proteins.

Electron Microscopy Keratinocytes were plated at 5000 cells/ $\mathrm{cm}^{2}$ and grown on Cyclopore membranes (Falcon, Heidelberg, Germany) for $3 \mathrm{~d}$. The concentration of $\mathrm{Ca}^{++}$was raised from $0.1 \mathrm{mM}$ to $1.1 \mathrm{mM}$ for $3 \mathrm{~h}$, and cells were then fixed with $4 \%$ glutaraldehyde for $30 \mathrm{~min}$ at $4^{\circ} \mathrm{C}$, post-fixed in $\mathrm{OsO}_{4}$, and embedded in Epon 812. Ultrathin sections were counterstained in uranyl acetate and examined in a Zeiss EM 9 electron microscope. Human skin was fixed in half-strength Karnovsky's fixative, embedded in Epon, stained with uranyl acetate and lead acetate, processed, and examined in a JEM 100B electron microscope.

Immunofluorescence Skin and gingival mucosa biopsies were cut into $1-\mathrm{mm}^{3}$ pieces, frozen in isopentane pre-cooled with liquid nitrogen, and stored at $-70^{\circ} \mathrm{C}$ until use. Four-micrometer sections were cut on a cryostat. Monkey esophagus sections, usually used as substrate in routine diagnostic testing for bullous diseases, were purchased from Bios $\mathrm{GmbH}$, Munich, Germany; the sections were taken from the middle third of the esophagus. Cultured keratinocytes were grown on coverslips for $3 \mathrm{~d}$ before the formation of intercellular contacts was induced for $3 \mathrm{~h}$ by $1.1 \mathrm{mM} \mathrm{Ca}^{++}$. Cells were then fixed in $2 \%$ formaldehyde for $30 \mathrm{~min}$ and permeabilized with $0.2 \%$ Triton X-100 in TBS containing $0.1 \mathrm{mM} \mathrm{Ca}{ }^{++}$. Further incubation steps were the same as for tissue sections and cells. Nonspecific binding was reduced by blocking with $2 \%$ bovine serum albumin (ICN, Meckenheim, Germany) for $30 \mathrm{~min}$ at $25^{\circ} \mathrm{C}$. The primary antibody, anti-vinculin immunoglobulin G (ICN, Meckenheim, Germany), was applied for $30 \mathrm{~min}$ at $25^{\circ} \mathrm{C}$ diluted in TBS containing $0.1 \mathrm{mM}$ calcium and $2 \%$ bovine serum albumin (BSA); washed with the same buffer without BSA, and then incubated with rhodamine-conjugated goat anti-mouse secondary antibody (Dianova, Hamburg, Germany). Coverslips were washed again and mounted in $40 \%$ glycerol. Cells and sections were examined with a Zeiss Axiophot microscope equipped with epifluorescence and photographed with Kodak Tri-X pan film processed in Ultrafin SF (Tetenal, Norderstedt, Germany) at 400 ASA.

\section{RESULTS}

Presence of Vinculin in Human Epidermis by Immunofluorescence To test for the presence of vinculin in human skin, cryostat sections were incubated with monoclonal antibodies against vinculin. This antibody labeled all epidermal layers except the stratum corneum (Fig 1A), but there were differences in the fluorescence intensity of different layers. In the basal layer strong fluorescence was present in the area of the plasma membrane at sites of cell-cell contact. In addition, intense, band-like staining was present at the dermal-epidermal junction and was of similar intensity in all areas of the dermal-epidermal junction. In the spinous layer, the fluorescence was less intense; the strongest suprabasal staining was detected in the stratum granulosum. Fluorescence was confined to the region of the plasma membrane; intracellular staining was minimal or absent.

In another stratified epithelium, the oral mucosa, antibodies to vinculin stained cell-cell junctions of keratinocytes. At the connective tissue-epithelial interface an intense linear fluorescence was present, similar to that of the dermal-epidermal junction in human skin described above (Fig 1B,C). Differences in intensity of fluorescence between the layers of epithelium were less obvious in oral mucosa, which was stained in a more homogeneous fashion.

Monkey esophagus is often used for immunofluorescence for diagnosis of bullous diseases, in which the integrity of cell-cell or 

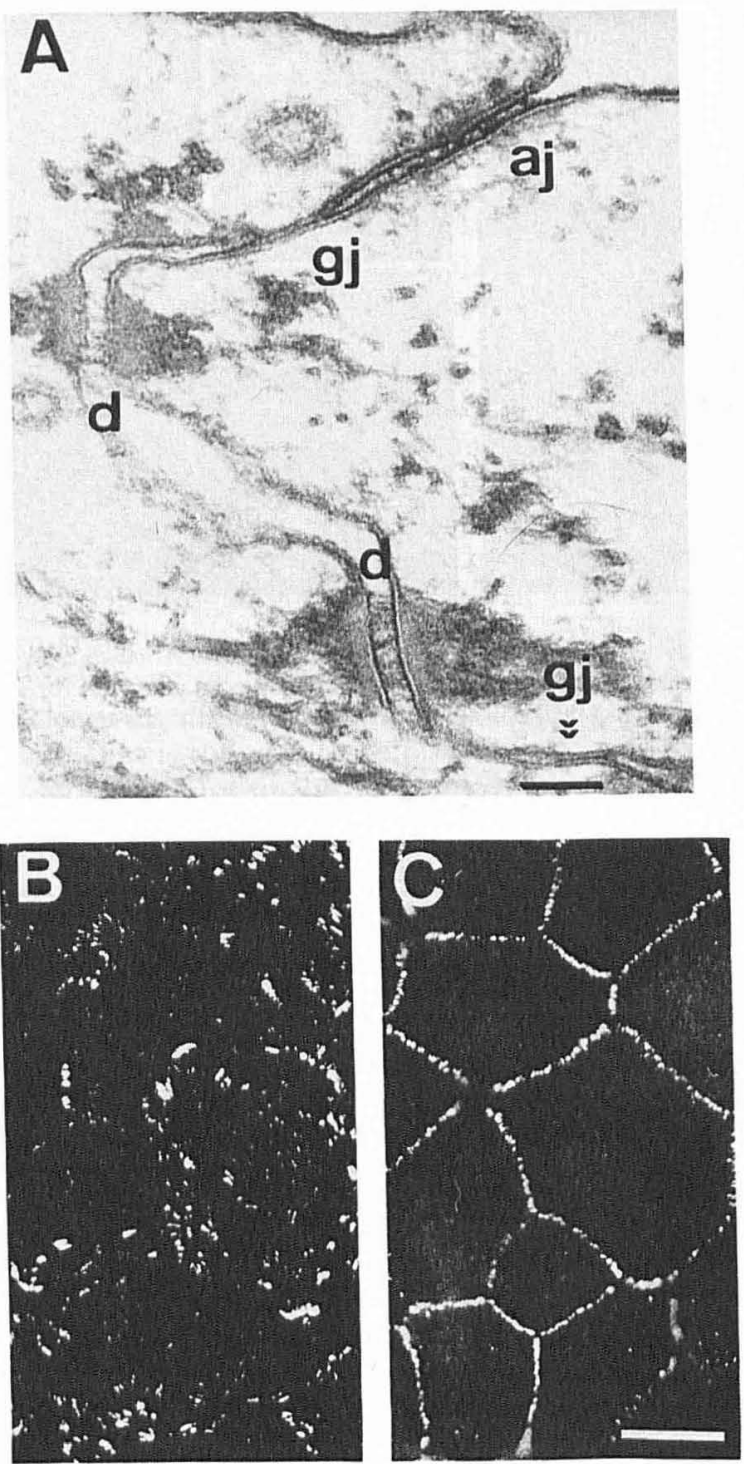

Figure 2. Adherens junctions and desmosomes in cultured human keratinocytes. Cells were cultured and fixed for electron microscopy $(A)$ or processed for immunofluorescence microscopy with antibodies to vinculin $(B, C)$ as in Materials and Methods. $A$, vertical section; $B, C$, en face section; in $B$, the focal plane is at the base of the cell at the junction of cell and substratum, showing focal adhesions; in $C$, the focal plane is higher, at the level of the cell-cell junction, showing cell-cell adherens junctions. aj, adherens junctions; gj, gap junctions; d, desmosomes. Bar, $0.4 \mu \mathrm{m}(A)$, $20 \mu \mathrm{m}(B, C)$.

cell-matrix contacts is disrupted by autoantibodies against junctional proteins. In studies of monkey esophagus (Fig $1 D, E$ ), antibodies against vinculin revealed fluorescence in the area of the plasma membrane similar to that in skin and oral mucosa (Fig $1 D)$. In some areas, a regular punctate pattern was noted at intercellular regions, indicating that vinculin was present at defined intercellular sites rather than in a general distribution along the entire plasma membrane, compatible with a distribution in discrete junctional structures. In addition, vinculin antibodies bound to the basal aspect of keratinocytes at the dermal-epidermal junction. As a control, we stained sections of monkey esophagus smooth muscle; anti-vinculin antibodies produced characteristic staining in this tissue (Fig 1E).

Adherens Junctions in Cultured Keratinocytes To compare these results with those in vitro, we examined cultured keratinocytes. Electron microscopy revealed structures in keratinocytes characteristic of adherens junctions in the apical portion of adjacent cells (Fig $2 A$ ). The intercellular space in this region contained elec-

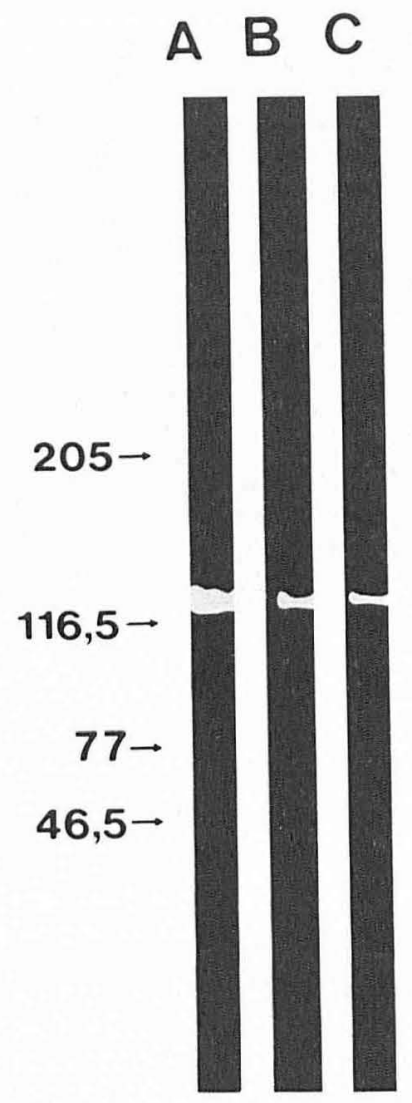

Figure 3. Demonstration of vinculin in epithelia or keratinocytes by western blotting. Keratinocytes were cultured in supplemented MCDB 153 medium with $0.1 \mathrm{mM} \mathrm{Ca}^{++}$for $3 \mathrm{~d}$ and then incubated in $1.1 \mathrm{mM}$ $\mathrm{Ca}^{++}$for $3 \mathrm{~h}$ before extraction as in Materials and Methods. Extracts of keratinocytes $(A)$, epidermis $(B)$, or gingival mucosa $(C)$ were analyzed by sodium dodecylsulfate polyacrylamide gel electrophoresis, transferred to nitrocellulose, and probed with antibody to vinculin. Numbers at left indicate molecular weights of standards in $\mathrm{kDa}$.

tron-dense material. Symmetric subplasmalemmal aggregates of electron-dense material representing microfilaments were associated with these structures. Below the level of adherens junctions additional junctional structures representing gap junctions and desmosomes were present. In cultured keratinocytes fixed and stained with anti-vinculin antibodies, by focusing on the base of the cells just above the plane of the glass coverslip we noted vinculin-containing structures characteristic of focal adhesions in plaques at the area of cell-matrix contact (Fig $2 B$ ). This staining at the basal aspect of the cell membrane is in agreement with previous studies demonstrating vinculin in focal adhesions of cultured cells $[11,17,18,21]$. Vinculin was also demonstrable at a higher focal plane at the lateral cell border of adjacent cells (Fig 2C) in a linear punctate pattern characteristic of intercellular junctions.

Immunoblotting of Vinculin We performed immunoblotting to confirm the finding by immunofluorescence that vinculin was present in epidermis. To exclude the dermis as a source for vinculin, the epidermis was separated from dermis by heating. Monoclonal anti-vinculin antibodies reacted with a single polypeptide band of $\mathrm{Mr} 130,000$ in homogenates of cultured keratinocytes (Fig 3A), and a band of the same Mr was detected with this antibody in homogenates of epidermis (Fig 3B) and oral mucosa (Fig 3C).

Presence of Adherens Junctions in Human Skin by Electron Microscopy We also examined human skin for the presence of structures with the appearance of adherens junctions. In human epidermis, typical desmosomes were numerous and were associated with structures characteristic of adherens junctions (Fig 4A). These 

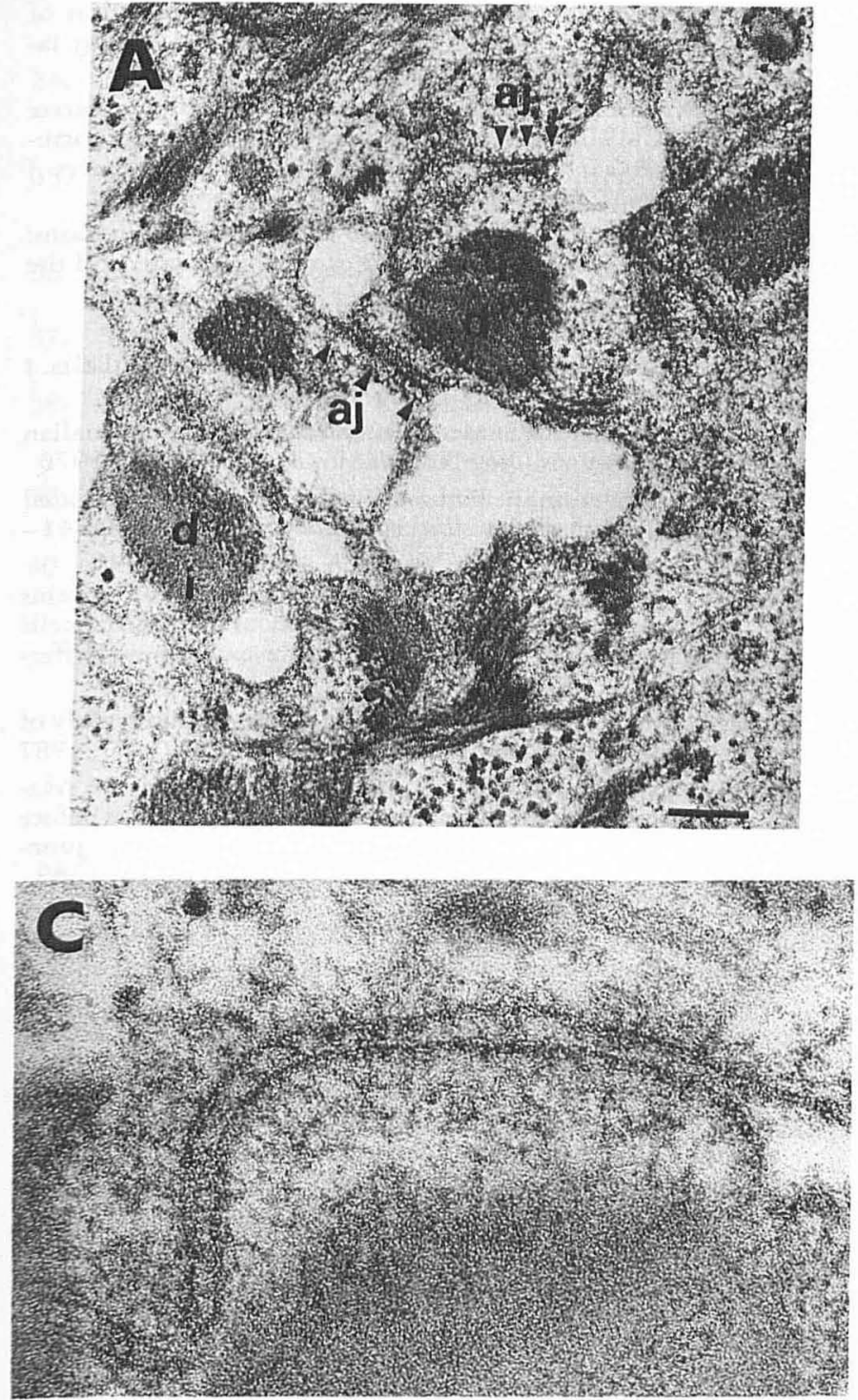

structures showed densities at cell-cell junctions that were not associated with darkly stained tonofilaments but often displayed a fine fuzz or granularity in the region of the intracellular plaque (Fig $4 B, C)$. Although adherens junctions are not as distinctive in their morphology as are desmosomes, they could be readily distinguished from desmosomes, because they lacked the complex laminar structure and darkly stained tonofilaments of desmosomes (shown in the lower half of Fig $4 B$ ), but rather showed granularity (Fig $4 B$ ) and in some cases fine filaments (Fig $4 C$ ) characteristic of adherens junctions.

\section{DISCUSSION}

This study provides strong evidence for the presence of adherens junctions in human epidermis as well as in other stratified epithelia, oral mucosa, and monkey esophagus. Two distinct locations were found for vinculin in these tissues and cultured keratinocytes. Vinculin was present in the area of cell-matrix contacts as well as in the area of cell-cell contacts. The first location is in agreement with the location of vinculin along the basal aspect of the cell membrane as described in cornea [7] and is consistent with the localization of vinculin in focal contacts in cultured keratinocytes ([17,18,21]; Fig $2 B$ ); fibroblasts [11,24]; embryonic chicken gizzard, heart, skin [25], and neurites [26]; and rat corneal epithelial cells [27].

The appearance of focal adhesions is often considered to be a feature of cultured cells, because they are very prominent in vitro but

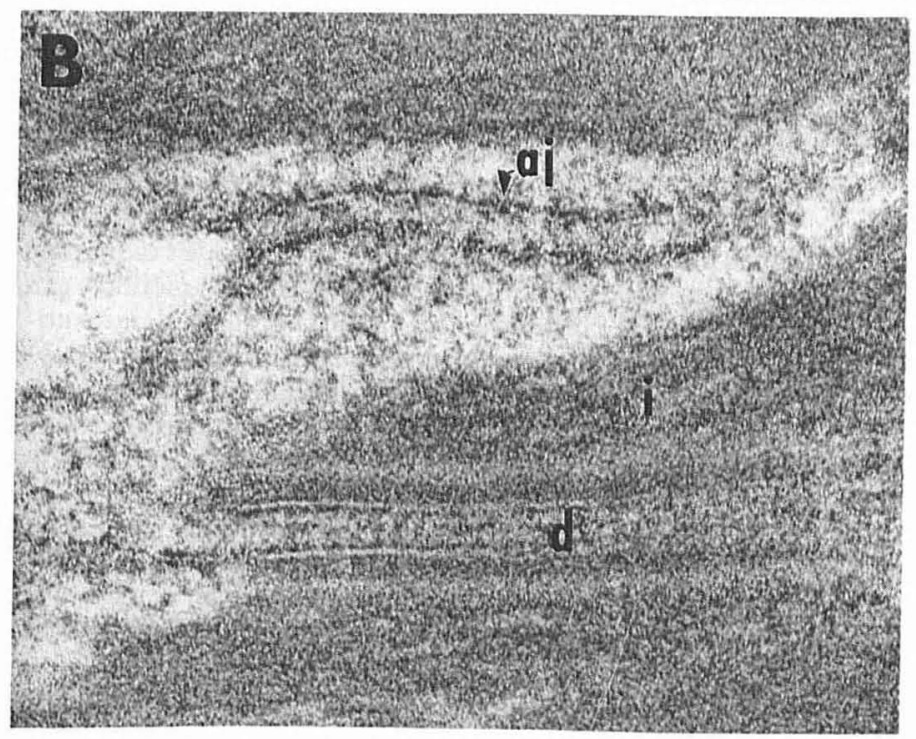

Figure 4. Adherens junctions in human epidermis. Human skin was processed for electron microscopy as in Materials and Methods. A, field showing adherens junctions and desmosomes; $B$ and $C$, enlargements showing characteristic appearance of adherens junctions. d, desmosomes; aj, adherens junctions; $\mathrm{i}$, intermediate filaments. Bar in $A, 0.2 \mu \mathrm{m}$ (A); $0.06 \mu \mathrm{m}(B, C)$. are difficult to demonstrate in vivo. Several types of cells, however, develop structures in vivo similar to focal adhesions found in cell culture. The dense plaques of smooth muscle, for example, which are present at points of contact between the extracellular matrix and the contractile microfilament system inside the muscle cell [28], have been found to contain proteins present in focal adhesions including vinculin [4,5], talin [29,30], and integrins [11]. Talin is found only in adherens junctions at the cell-matrix interface, not in adherens junctions at sites of cell-cell contact [11], both in vivo and in vitro. Recently, isoforms of integrin were detected in region of the basal lamina in epidermis [31,32]. In basal epidermal cells $\alpha 3 \beta 1$ integrin was strongly expressed in contact with the basal membrane zone [33], and co-localized with epiligrin, a glycoprotein of the basal membrane next to hemidesmosomes [34]. Experiments with cultured cells implicate integrins in cell-matrix adhesion in epidermis and in cell-cell adhesion in the basal layer of epidermis [35].

The second site of localization of vinculin is the region of cell-cell contact. Typical adherens junctions associated with microfilaments were found in electron microscopic studies of cultured keratinocytes $[17,18,20]$. These junctions probably correspond to the $70-\mathrm{F}$ macula adhaerens identified in developing heart by McNutt and Weinstein [14]. Similar structures, called type II plaques, have been demonstrated by other authors between Sertoli cells and germ cells in mammalian testis [36,37], intestinal epithelium [3], rat prostate epithelium [3], and cornea [3]. Although there is heterogeneity in 
the electron microscopic appearance of adherens junctions at sites of cell-cell contact, immunofluorescence studies show that the type II plaque, like the zonula adhaerens, contains vinculin, alpha-actinin, and actin. In the intercellular region of adherens junctions, transmembrane adhesion molecules of the cadherin family have been identified [38-41]. These calcium-dependent adhesion molecules mediate homotypic contact between cells $[39,42]$. One of the subtypes, A-CAM (N-Cadherin) is present adjacent to the intracellular plaque in lens cells $[40,41]$. Another isoform, uvomorulin (E-Cadherin, Arc-1, Cell Cam 120/80, or L-CAM) is associated with adherens junctions in intestinal epithelium [38].

These adhesion structures, which are distinct from desmosomes, may be important for understanding the pathogenesis of skin diseases that alter intercellular structures. Antibodies against cadherins, which are present in both desmosomes and adherens junctions, can induce acantholysis in cultured cells $[42,43]$. Pemphigus autoantibodies are believed to affect desmosomes but are directed at desmosomal glycoproteins that are members of the cadherin family [4446]; cadherins are also present in the adherens junctions. Genetic disorders affecting cell-cell adhesion may affect molecules such as cadherins in one or both of these adhering junctions.

Vinculin may also play an important role in wound healing in skin. Recent reports show a dramatic increase in vinculin after wounding of the cornea, indicating that synthesis of at least one adherens junction protein is markedly increased during wound healing [7]. Because vinculin is a marker for this type of junction, it is likely that other proteins required for assembly of adherens junctions are also increased and that the number of these junctions increases in response to a wound. This possibility has not been investigated in epidermis.

Because adherens junctions mediate both cell-cell and cell-matrix contact in various tissues, in contrast to desmosomes, which are confined primarily to epithelial cells, further studies are needed to examine the role of adherens junctions in the integrity of stratified epithelia. In addition, the relationship between staining for vinculin in the basal lamina in vivo and in the focal adhesion in vitro needs further examination in epidermis, because some adherens junction proteins, unlike vinculin, are present exclusively in either focal adhesions or in cell-cell adherens junctions, but not in both.

We thank Volker Hinz for skillful technical assistance. This work was supported in part by NIH grant AM 25871 to EJO'K and by the Deutsche Forschungsgemeinschaft $\mathrm{Ka} 852 / 1-1$.

\section{REFERENCES}

1. Overton J: Cell junctions and their development. Prog Surf Membr Sci 8:161-208, 1974

2. Staehelin LA: Structure and function of intercellular junctions. Int Rev Cytol 39:191-283, 1974

3. Drenckhahn D, Franz H: Identification of actin-, alpha-actinin-, and vinculin-containing plaques at the lateral membrane of epithelial cells. J Cell Biol 102:1843-1852, 1986

4. Geiger B, Dutton AH, Tokuyasu KT, Singer SJ: Immunoelectron microscope studies of membrane-microfilament interactions: distributions of alpha-actinin, tropomyosin, and vinculin in intestinal epithelial brush border and chicken gizzard smooth muscle cells. J Cell Biol 91:614-628, 1981

5. Geiger B, Tokuyasu KT, Dutton AH, Singer SJ: Vinculin, an intracellular protein localized at specialized sites where microfilament bundles terminate at cell membranes. Proc Natl Acad Sci USA 77:4127-4131, 1980

6. Koteliansky VE, Gneushev GN: Vinculin localization in cardiac muscle. FEBS Lett 159:158-160, 1983

7. Zieske JD, Bukusoglu G, Gipson IK: Enhancement of vinculin synthesis by migrating stratified squamous epithelium. J Cell Biol 109:571-576, 1989

8. Geiger B, Volk T, Volberg T, Bendori R: Molecular interactions in adherens-type contacts. J Cell Sci Suppl 8:251-272, 1987
9. Abercrombie M, Heaysman JEM, Pegrum SM: The locomotion of fibroblasts in culture. IV. Electron microscopy of the leading lamella. Exp Cell Res 67:359-367, 1971

10. Takada Y, Wayner EA, Carter WG, Hemler ME: Extracellular matrix receptors, ECMRII and ECMRI, for collagen and fibronectin correspond to VLA-2 and VLA-3 in the VLA family of heterodimers. J Cell Biochem 37:385-393, 1988

11. Burridge K, Fath K, Kelly T, Nuckolls G, Turner C: Focal adhesions: transmembrane junctions between the extracellular matrix and the cytoskeleton. Ann Rev Cell Biol 4:487-525, 1988

12. Otto JJ: Vinculin. Cell Motil Cytoskeleton 16:1-6, 1990

13. Farquhar MG, Palade GE: Junctional complexes in various epithelia. J Cell Biol 17:375-412, 1963

14. McNutt NS, Weinstein RS: Membrane ultrastructure at mammalian intercellular junctions. Prog Biophys Mol Biol 26:47-101, 1973

15. Rodewald R, Newman SB, Karnovsky MJ: Contraction of isolated brush borders from the intestinal epithelium. J Cell Biol 70:541554, 1976

16. Geiger B, Schmid E, Franke WW: Spatial distribution of proteins specific for desmosomes and adhaerens junctions in epithelial cells demonstrated by double immunofluorescence microscopy. Differentiation 23:189-205, 1983

17. O'Keefe EJ, Briggaman RA, Herman B: Calcium-induced assembly of adherens junctions in keratinocytes. J Cell Biol 105:807-817, 1987

18. Green KJ, Geiger B, Jones JCR, Talian JC, Goldman RD: The relationship between intermediate filaments and microfilaments before and during the formation of desmosomes and adherens-type junctions in mouse epidermal keratinocytes. J Cell Biol 104:13891402,1987

19. Rheinwald J, Green H: Epidermal growth factor and the multiplication of cultured human epidermal keratinocytes. Nature (London) 265:421-424, 1977

20. Boyce ST, Ham RG: Calcium-regulated differentiation of normal human epidermal keratinocytes in chemically defined clonal culture and serum-free serial culture. J Invest Dermatol 81:33S-40S, 1983

21. Kaiser HW, O'Keefe E, Bennet V: Adducin: $\mathrm{Ca}^{++}$-dependent association with sites of cell-cell contact. J Cell Biol 109:557-569, 1989

22. Fairbanks G, Steck TL, Wallach DFH: Electrophoretic analysis of the major polypeptides of the human erythrocyte membrane. Biochem 13:2606-2617, 1971

23. Towbin H, Staehelin T, Gordon J: Electrophoretic transfer of proteins from polyacrylamide gels to nitrocellulose sheets: procedure and some applications. Proc Natl Acad Sci USA 76:4350-4354, 1979

24. Geiger B, Avnur Z, Rinnerthaler G, Hinssen H, Small VJ: Microfilament-organizing centers in areas of cell contact: cytoskeletal interactions during cell attachment and locomotion. J Cell Biol 99:83S91S, 1984

25. Geiger B: A $130 \mathrm{~K}$ protein from chicken gizzard: its localization at the termini of microfilament bundles in cultured chicken cells. Cell 18:193-205, 1979

26. Halegoua $\mathrm{S}$ : Changes in the phosphorylation and distribution of vinculin during nerve growth factor induced neurite outgrowth. Dev Biol 121:97-104, 1987

27. Soong HK: Vinculin in focal cell-to-substrate attachments of spreading corneal epithelial cells. Arch Ophthalmol 105:1129-1132, 1987

28. Small JV: Geometry of actin-membrane attachments in the smooth muscle cell: the localisations of vinculin and alpha-actinin. EMBO J 4:45-49, 1985

29. Drenckhahn D, Beckerle M, Burridge K, Otto J: Identification and subcellular location of talin in various cell types and tissues by means of [ $\left.{ }^{125} I\right]$ vinculin overlay, immunoblotting and immunocytochemistry. Eur J Cell Biol 46:513-522, 1988

30. Geiger B, Volk T, Volberg T: Molecular heterogeneity of adherens junctions. J Cell Biol 101:1523-1531, 1985

31. Zambruno G, Manca V, Santantonio ML, Soligo D, Gianetti A: VLA protein expression on epidermal cells (keratinocytes, Langerhans cells, melanocytes): a light and electron microscopic immunohistochemical study. Br J Derm 124:135 - 145, 1991

32. Ryynänen J, Jaakkola S, Engvall E, Peltonen J, Uitto J: Expression of $\beta 4$ integrins in human skin: Comparison of epidermal distribution with $\beta 1$-integrin epitopes, and modulation by calcium and vitamin $\mathrm{D}_{3}$ in cultured keratinocytes. J Invest Dermatol 97:562 - 576, 1991

33. Carter WG, Wayner EA, Bouchard TS, Kaur P: The role of integrins 
$\alpha 2 \beta 1$ and $\alpha 3 \beta 1$ in cell-cell and cell-substrate adhesion of human epidermal cells. J Cell Biol 110:1387-1404, 1990

34. Carter WG, Ryan MC, Gahr PJ: Epiligrin, a new cell adhesion ligand for integrin $\alpha 3 \beta 1$ in epithelial basement membranes. Cell 65:599 610,1991

35. Larjava H, Peltonen J, Akiyama SK, Yamada SS, Gralnick HR, Uitto J, Yamada KM: Novel function for $\beta 1$ integrins in keratinocyte cellcell interactions. J Cell Biol 110:803-815, 1990

36. Russell L: Desmosome-like junctions between Sertoli and germ cells in the rat testis. Am J Anat 148:301-312, 1977

37. Toyama Y: Actin-like filaments in the Sertoli cell junctional specializations in the swine and mouse testis. Anat Rec 186:477-492, 1976

38. Boller K, Vestweber D, Kemler R: Cell-adhesion molecule uvomorulin is localized in the intermediate junctions of adult intestinal epithelial cells. J Cell Biol 100:327-332, 1985

39. Nose A, Nagafuchi A, Takeichi M: Expressed recombinant cadherins mediate cell sorting in model systems. Cell 54:993-1001, 1988

40. Volk T, Geiger B: A 135-kd membrane protein of intercellular adherens junctions. EMBO J 3:2249-2260, 1984
41. Volk T, Geiger B: A-CAM: a 135-kD receptor of intercellular adherens junctions. I. Immunoelectron microscopic localization and biochemical studies. J Cell Biol 103:1441-1450, 1986

42. Takeichi M: Cadherin cell adhesion receptors as a morphogenetic regulator. Science 251:1451-1455, 1991

43. Duband JL, Dufour S, Hatta K, Takeichi M, Edelman GM, Thiery JP: Adhesion molecules during somitogenesis in the avian embryo. J Cell Biol 104:1361-1374, 1987

44. Eyre RW, Stanley JR: Human autoantibodies against a desmosomal protein complex with a calcium-sensitive epitope are characteristic of pemphigus foliaceus patients. J Exp Med 165:1719-1724, 1987

45. Koulu L, Kusumi A, Steinberg MS, Klaus-Kovtun V, Stanley JR: Human autoantibodies against a desmosomal core protein in pemphigus foliaceus. J Exp Med 160:1509-1518, 1984

46. Amagai M, Klaus-Kovtun V, Stanley JR: Autoantibodies against a novel epithelial cadherin in pemphigus vulgaris, a disease of cell adhesion. Cell 67:869-877, 1991

\section{ANNOUNCEMENT}

The guidelines for manuscripts and the editorial office of The Journal of Investigative Dermatology have changed. Please see the new Information for Authors in this issue. 